\title{
SITE BARRIER OPTIMIZATION ON INTEGRATING THERMAL COMFORT WITH NOISE PROPAGATION CONTROL
}

\author{
FX Teddy Badai Samodra \\ Department of Architecture, Institut Teknologi Sepuluh Nopember, \\ Kampus ITS, Sukolilo, Surabaya 60111, INDONESIA \\ Email: fxteddybs@arch.its.ac.id
}

\begin{abstract}
The difference in geographical altitudes in tropical environment not only causes variations in climate and environment leading to influences on thermal comfort, but also effects on noise propagation variation. This study proposes the site barrier optimization and integrated control on thermal performance and environmental noise to reach the standards using ANSYS Fluent and MATLAB simulations method. The research locations are in Surabaya as the lowland area and Malang as highland area, all are representatives of tropical urban environment of Indonesia. The results highlighted that the minimum barrier distance to receiver for the lowest barrier height $(1.5 \mathrm{~m})$ for both thermal and noise improvement is $5.63 \mathrm{~m}$. Meanwhile, at minimum distance for noise control $(1.8 \mathrm{~m})$, the minimum reference height of aperture is $1.02 \mathrm{~m}$ when it uses lowest barrier height.
\end{abstract}

Keywords: Noise control; site barrier; thermal comfort.

\section{INTRODUCTION}

Under the condition of an urban environment, heat and noise simultaneously effect the indoor environment in addition to lighting and indoor air quality. The standard of indoor environment determines the different environmental factors, such as thermal, indoor air quality, aural and visual environment comfort (Huang et al., 2012). Furthermore, an examination on the acceptable range of every individual environmental factor as well as the simultaneous effects of universal factors is needed. The environmental problems of heat and noise are considered the most important contributors to the indoor environmental quality (Lai et al., 2009). Thermal acceptance would decrease at any operative temperature greater than $29.8^{\circ} \mathrm{C}$ and the thermal environment would become unacceptable at operative temperatures greater than $32.8^{\circ} \mathrm{C}$. A significant decrease in the acceptance was also found when the noise level exceeded $70 \mathrm{dBA}$ and noise is one of the obstacles to the application of natural ventilation (Ghiaus et al., 2006). On the other hand, the opened and porous walls of buildings can help to provide a solution for this result. This ventilation strategy for cooling and dehumidification, however, can allow air borne noise transfer from outdoors to indoors when the wind is in the same direction as the noise source (Samodra et al., 2014).

Indonesia is a ring of fire area as indicated by the presence of volcanoes and the effects they have on the country's topographical pattern which consists of lowland and highland altitudes (Figure 1). The difference in geographical altitudes not only causes variations in climate and environment leading to influences on thermal comfort, but also affects the difference in city growth because lowland cities usually grow faster than highland cities, which in turn has consequences on noise propagation variation. Based on background issues above, this paper studies the optimization of site barrier of tropical building as one of noise control strategy in urban environment (Figure 2). Furthermore, its optimized design should compromise the wind acceleration for thermal comfort by physiological cooling. The research locations are in Surabaya $\left(7.2^{\circ} \mathrm{S}, 112^{\circ} \mathrm{E}, 3 \mathrm{~m}\right.$ above mean sea level) as the lowland area and Malang $\left(7.8^{\circ} \mathrm{S}, 112^{\circ} \mathrm{E}, 575 \mathrm{~m}\right.$ above mean sea level) as highland area, all are representatives of tropical urban environment of Indonesia (see Figure 1).

\section{METHODOLOGY}

This study analyzes site barrier performance using ANSYS Fluent (CFD=Computational Fluid Dynamics) and MATLAB (Matrix Laboratory) for thermal and noise control evaluation, respectively. To improve both thermal and noise environment, site barrier is designed for reaching Field Study and WHO noise limits and general airflow minimum requirement. Airflow is obtained when the receiver (building) is not in leeward position of air movement (Figure 3). For the single and simple barrier, the leeward distance is determined as 3.75 of barrier height (Boutet, 1987, p.64). Meanwhile, Figure 4 shows the CFD meshing for object study for analyzing natural ventilation (inlet: velocity inlet; outlet: outflow). 


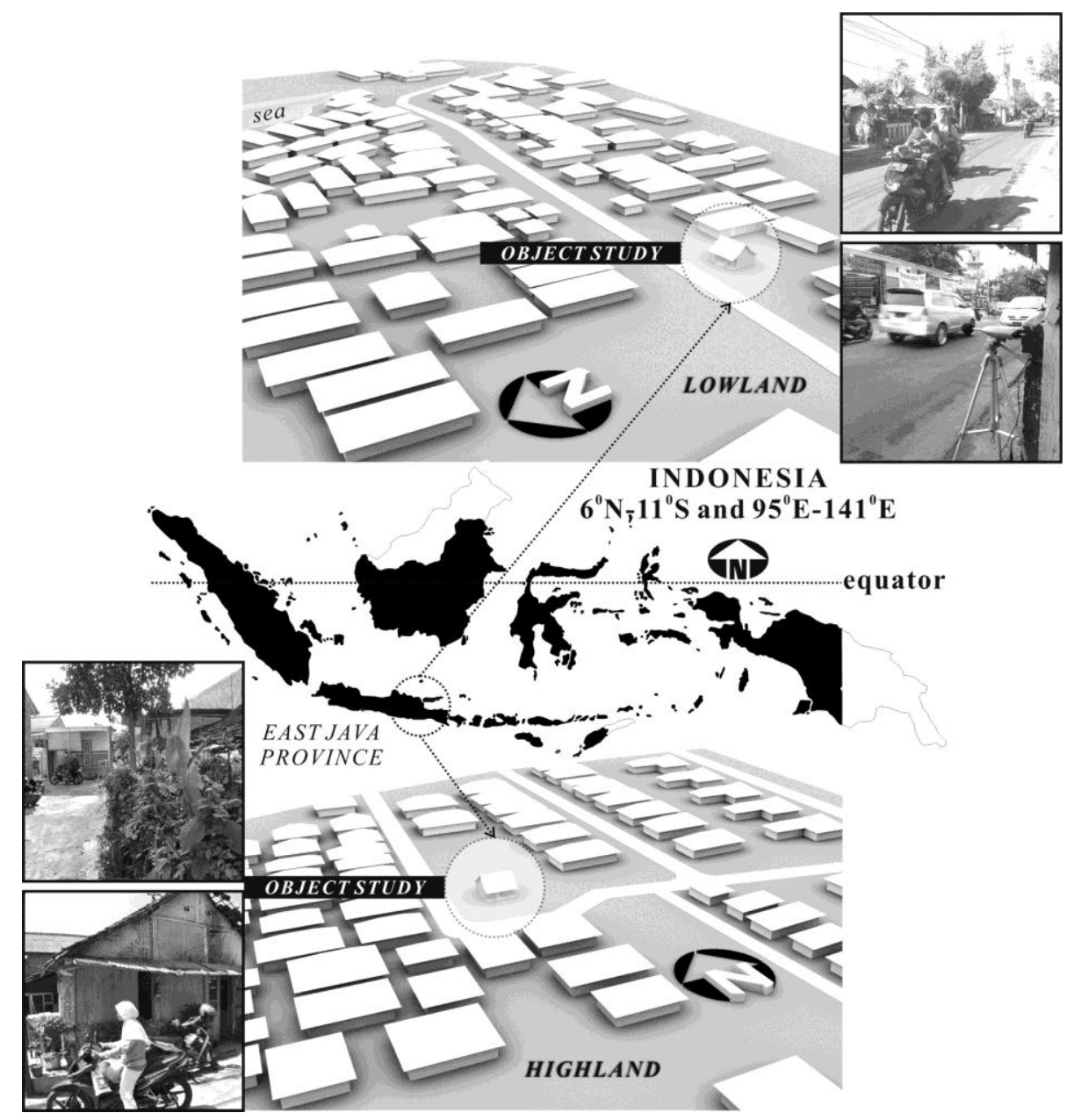

Fig. 1. Research Location

(Source: field survey, 2012-2014).

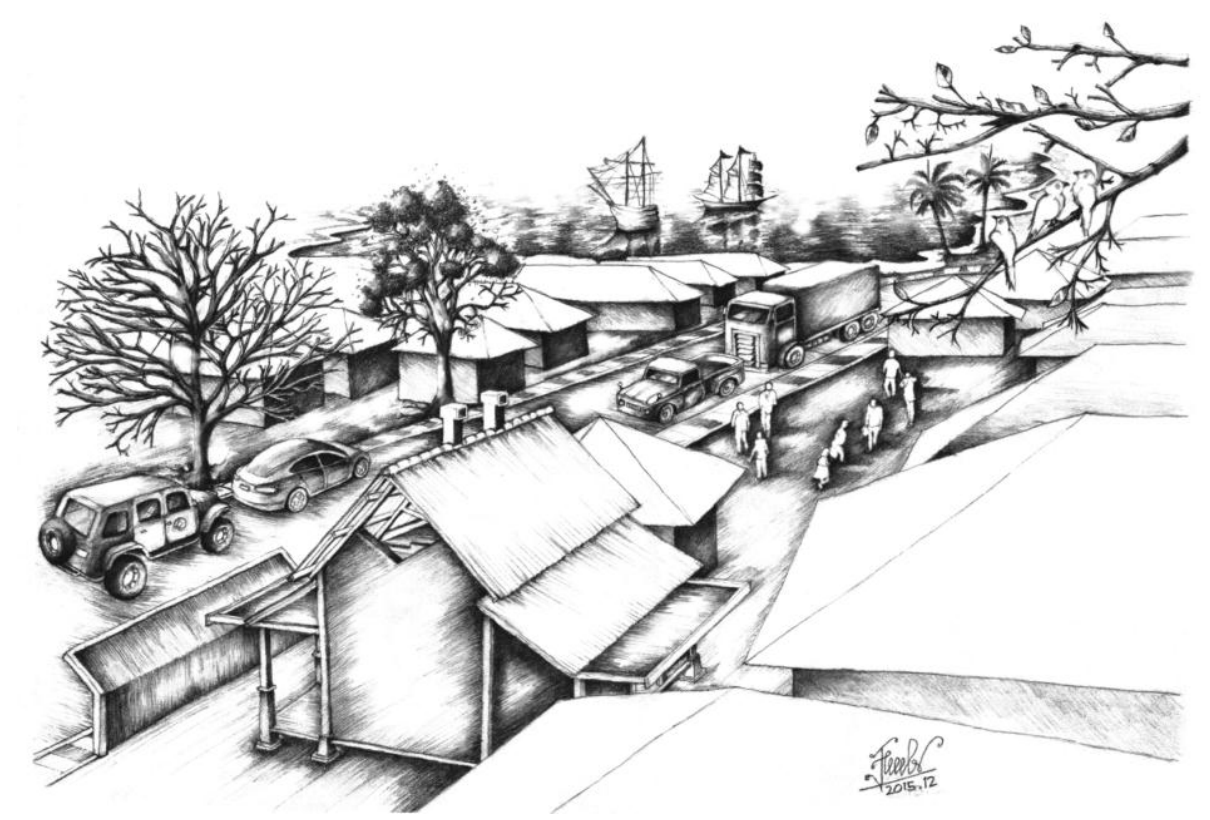

Fig. 2. Environmental Condition and Site Barrier Placement 


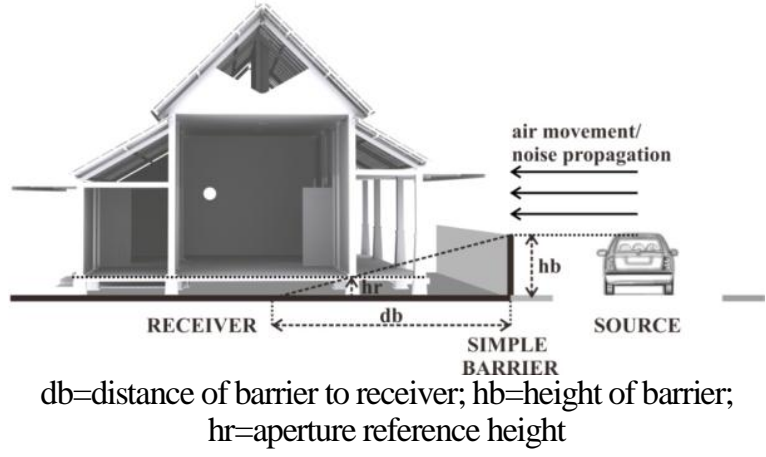

Fig. 3. Setting for Distance of Barrier to Receiver
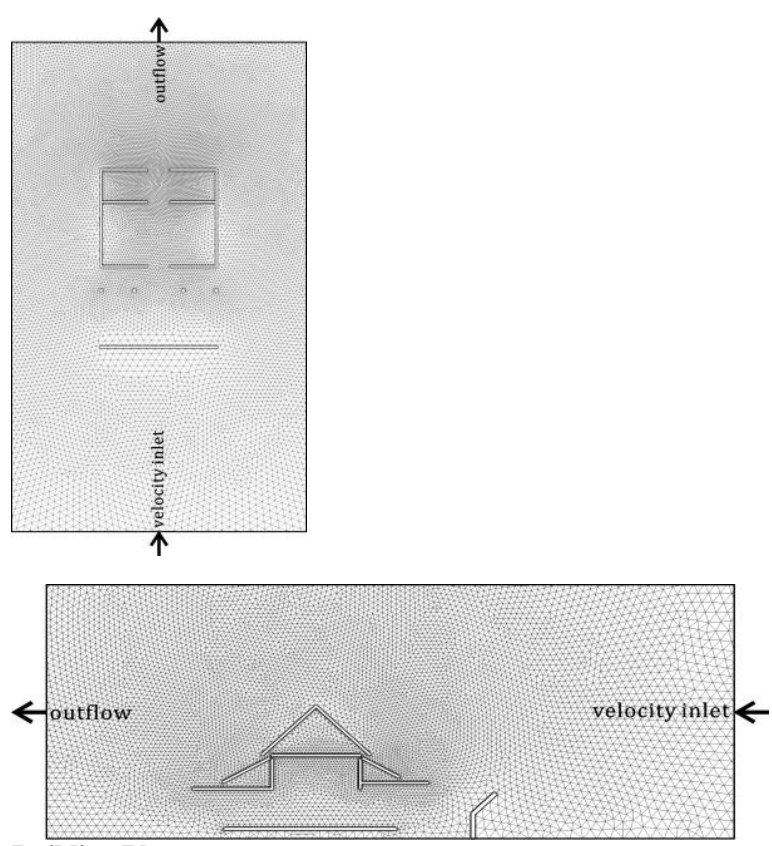

Building Plan:

Level=0; Cells $=56079 ;$ Faces $=84442$; Nodes $=28357$; Partitions $=1$ Building Section: Level=0; Cells $=21340$; Faces $=32273$; Nodes $=10927 ;$ Partitions $=1$

Fig. 4. CFD Meshing for Object Study

\section{RESULTS and DISCUSSION}

\section{Analysis of Wind Speed for Physiological Cooling}

This section evaluates wind speed requirement condition for dealing physiological cooling of thermal comfort with its control for noise reduction. It is directed to analyze minimum wind speed (air velocity) for physilogical cooling (Aynsley et al., 1977: p.181-183; Aynsley \& Spruill, 1990: p.483484). Adjustments to the comfort zones for specific local conditions are:

1. Decrease comfortable dry-bulb temperatures by $0.8^{\circ} \mathrm{C}$ for each $10 \%$ increase in relative humidity (RH) above $60 \%$.

2. Decrease comfortable dry-bulb temperatures by $0.55^{\circ} \mathrm{C}$ for each $2.8^{\circ} \mathrm{C}$ that the mean of surface temperatures of nearby radiating surfaces (mean radiant temperature, MRT) exceeds $38^{\circ} \mathrm{C}$.
3. Increase comfortable dry-bulb temperatures by $0.55^{\circ} \mathrm{C}$ for each $0.15 \mathrm{~m} / \mathrm{s}$ of air velocity for drybulb temperatures below $37^{\circ} \mathrm{C}$.

These criteria can be used to estimate the air velocity needed to restore thermal comfort, $\mathrm{Vc}$, at locations of less than 30-degree latitude (tropical warm humid climate) by using Equation 1 below:

$\mathrm{Vc}=0.15\left(\mathrm{DBT}-\mathrm{UCT}+\left(0.8^{*}((\mathrm{RH}-60) / 10)\right)+\right.$ $\left.\left(0.55^{*}(\mathrm{MRT} 38) / 2.8\right)\right)$

\section{Where:}

$\mathrm{Vc}$ : Wind speed requirement for physiological cooling $[\mathrm{m} / \mathrm{s}]$

DBT : Dry-Bulb Temperature/Air temperature $\left[{ }^{\circ} \mathrm{C}\right]$

UCT : Upper Dry-bulb Temperature $\left[{ }^{\circ} \mathrm{C}\right]$

RH : Relative Humidity [\%]

MRT : Mean Radiant Temperature $\left[{ }^{\circ} \mathrm{C}\right]$

In lowland daytime, based on field measurement data input and Equation 1, the building needs average minimum $1.5 \mathrm{~m} / \mathrm{s}$ of wind speed requirement. Meanwhile, in highland daytime, it requires only 0.8 $\mathrm{m} / \mathrm{s}$ of average minimum of wind speed. Night-time conditions in both lowland and highland, buildings do not need wind for physiological cooling because of their lower air temperature and MRT than daytime.

The proposed building with site barrier has consequences on air movement distribution in building. The ANSYS Fluent (CFD) simulation was conducted to analyze the wind speed of the building in the case of the same direction between wind and noise propagation from source to receiver. Figure 5 illustrates wind speed simulation in building plan and section of proposed building in lowland using overhang barrier based on input from field survey (2012-2014). Generally, the wind distribution is unfavorable condition in night-time. However, the lower night-time temperature is advantage for reaching requirement of wind speed for physiological cooling. Higher wind speed in opened area such as corridor, is still resulted by turbulence of site barrier. Barrier gives chance for horizontal air movement in room. Although it has low inflow, barrier results problem in height of air distribution only.

Figure 6 shows the site barrier performance in highland condition. The input of highland climate data shows lower wind speed both daytime and nighttime compared to the lowland that has opened area (field survey, 2012-2014). However, with cooler environment, the wind speed factor in this location is not as important as in lowland building. In terms of frontal wind direction to the building and site barrier, the leeward area does not interrupt air movement to the building with terrace, transitional area, as space for air temperature reduction. Site barrier that directed into frontal wind direction reduces wind speed in building certainly, but the distribution is still maintained with higher speed than input and accommo- 


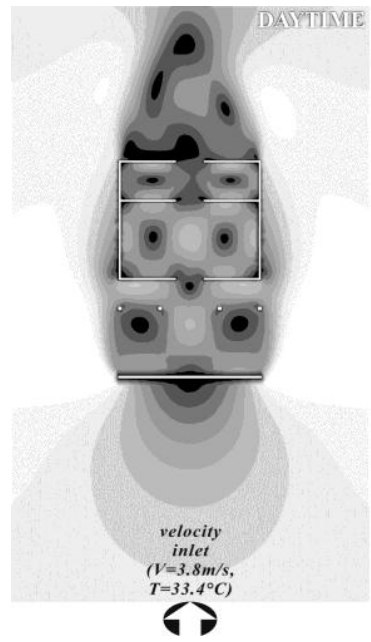

(plan)

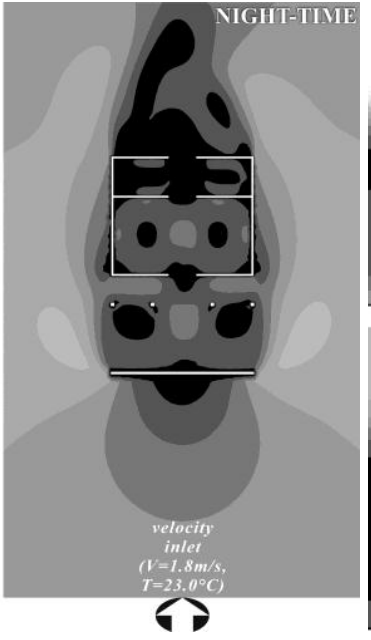

$\rightarrow$

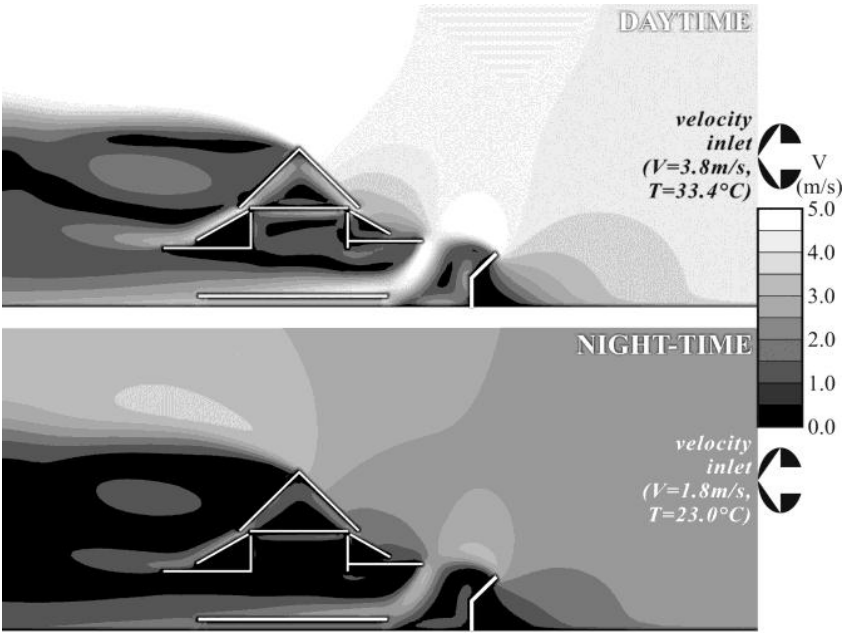

(section)

Fig. 5. Lowland wind speed simulation

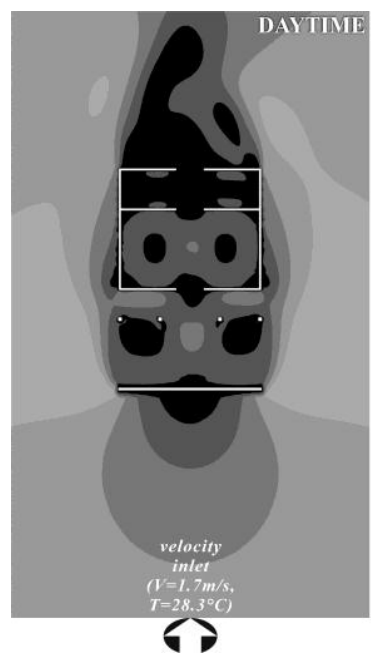

(plan)

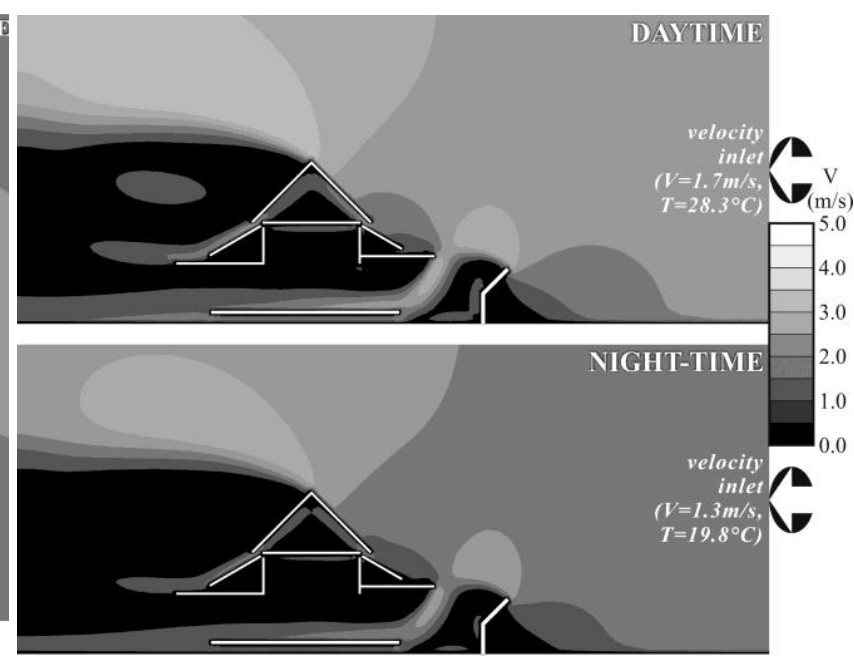

(section)

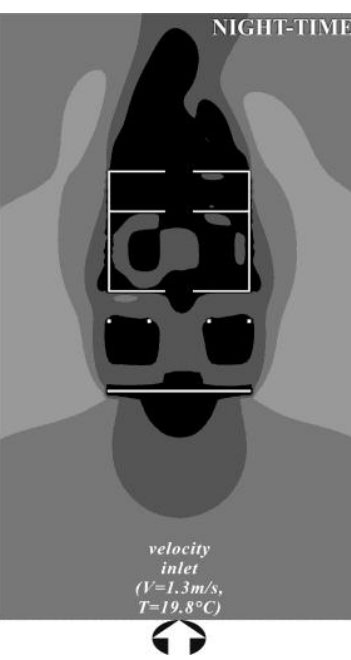

Fig. 6. Highland wind speed simulation dates occupant activities reference height. In general, the contour pattern in highland is the same with the lowland, but the wind speed is higher than the requirements.

\section{Analysis of Noise Propagation Control}

Considering the decay by distance owing to geometrical spreading, Sakamoto (2015) offered an engineering method of calculating outdoor noise propagation. It consisted of the diffraction effect, ground absorption and attenuation of sound due to atmospheric absorption. The A-weighted sound pressure level, LA,i, for noise propagation from the $i$ th source position to the prediction point is calculated for noise environment of tropical building. In this section, the study focuses on diffraction and ground effect evaluation where the absorption of air was also discussed as simultaneous factor with distance factor in building noise propagation.

Samodra (2015) showed that based on the survey results, noise limit in the daytime of lowland is $49.9 \mathrm{dBA}$ while for daytime in highland is $47.8 \mathrm{dBA}$. Night-time noise limits for the lowland and highland are $45.9 \mathrm{dBA}$ and $40.0 \mathrm{dBA}$, respectively. Meanwhile, the World Health Organization (WHO) recommends a maximum limit for the noise during the daytime is $35.0 \mathrm{dBA}$ and $30.0 \mathrm{dBA}$ for night-time (Berglund et al, 2000). Both of the criteria are useful to guide the determining of optimization; Based on the survey results or the survey standards and based on the recommendation of $\mathrm{WHO}$ or WHO standards. The building noise propagation is analyzed by Equation 2 and Equation 3 based on road traffic noise prediction model "ASJ RTN-Model 2008 and 2013." 
LA,i $=$ LWA, $-8-20 \log$ ri $+\Delta$ Lcor,I

$\Delta$ Lcor, $\mathrm{i}=\Delta$ Ldif, $\mathrm{i}+\Delta$ Lgrnd, $\mathrm{i}+\Delta$ Lair, $\mathrm{i}$

LA,i : Noise propagation from the $i$ th source position to the prediction point $[\mathrm{dB}]$

LWA,i : The A-weighted sound power level of a single running vehicle at the $i$ th source position [dB]

ri : The direct distance from the ith source position to the prediction point $[\mathrm{m}]$

$\Delta \mathrm{Lcor}, \mathrm{i}:$ The correction related to various attenuation factors in the sound propagation from the $i$ th source position to the prediction point $[\mathrm{dB}]$

$\Delta$ Ldif,i : The correction for diffraction [dB]

$\Delta$ Lgrnd,i : The correction for the ground effect [dB]

$\Delta$ Lair,i : The correction for atmospheric absorption $[\mathrm{dB}]$

For optimum result as CFD simulation above and for accelerating wind to building on case wind direction from road as main source to building, the overhang barrier is offered with consideration of similar capability as simple barrier to control the noise. Figure 7 shows the similar performance of overhang barrier compared to the simple one. This is the result from example of one case in lowland daytime. With the regression 0.944 , the closed relationship is assumed as the consideration of hypothetical simple barrier of overhang barrier (simplification of calculation). Actually, there is different SPL (Sound Pressure Level) for about 58 $\mathrm{dBA}$ of simple barrier compared to about $38 \mathrm{dBA}$ of overhang barrier where it indicates overhang role to enclose the road noise. However, the rest of the results on all point of calculation are similar in linear trend line. In case of the optimization of site barrier, all the correction related to various attenuation factors should be involved (diffraction, ground effect, and atmospheric absorption). This method is calculated by MATLAB programming

Figure 8 is total noise propagation both in lowland and highland resulted by the MATLAB programming. The overhang barrier is very important when the door is scheduled by occupant in opened condition for activity circulation reason or accelerating wind for physiological cooling. From 4 conditions, lowland/daytime is the most critical condition. However, it reaches the WHO noise limits ( $<35 \mathrm{dBA})$. The same condition is also complied by highland/daytime with $64.9 \mathrm{dBA}$ only of sound pressure level from noise source. Although, it has more stringent noise limits in night-time (WHO recommends, $30 \mathrm{dBA}$ ), both buildings in lowland and in highland comply with the standard.

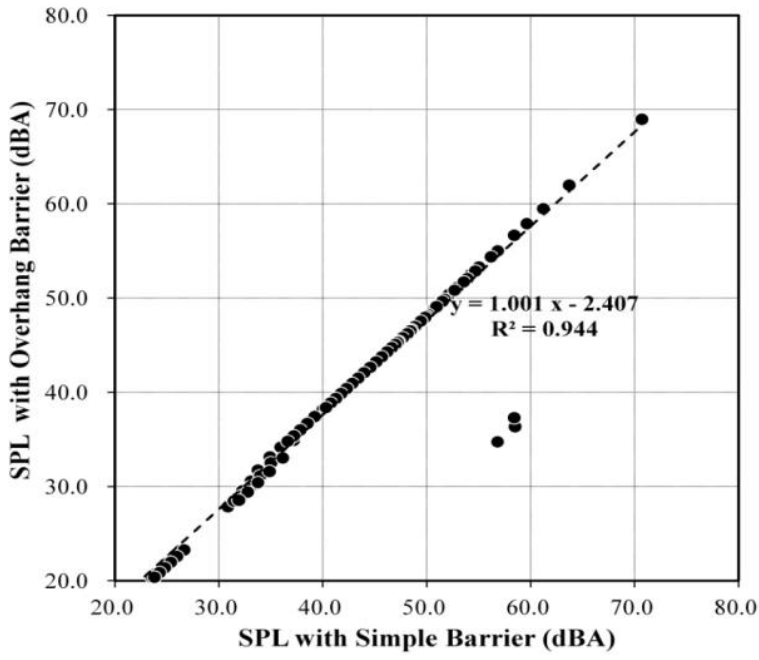

Fig. 7. Noise propagation comparison for building using simple barrier and overhang barrier
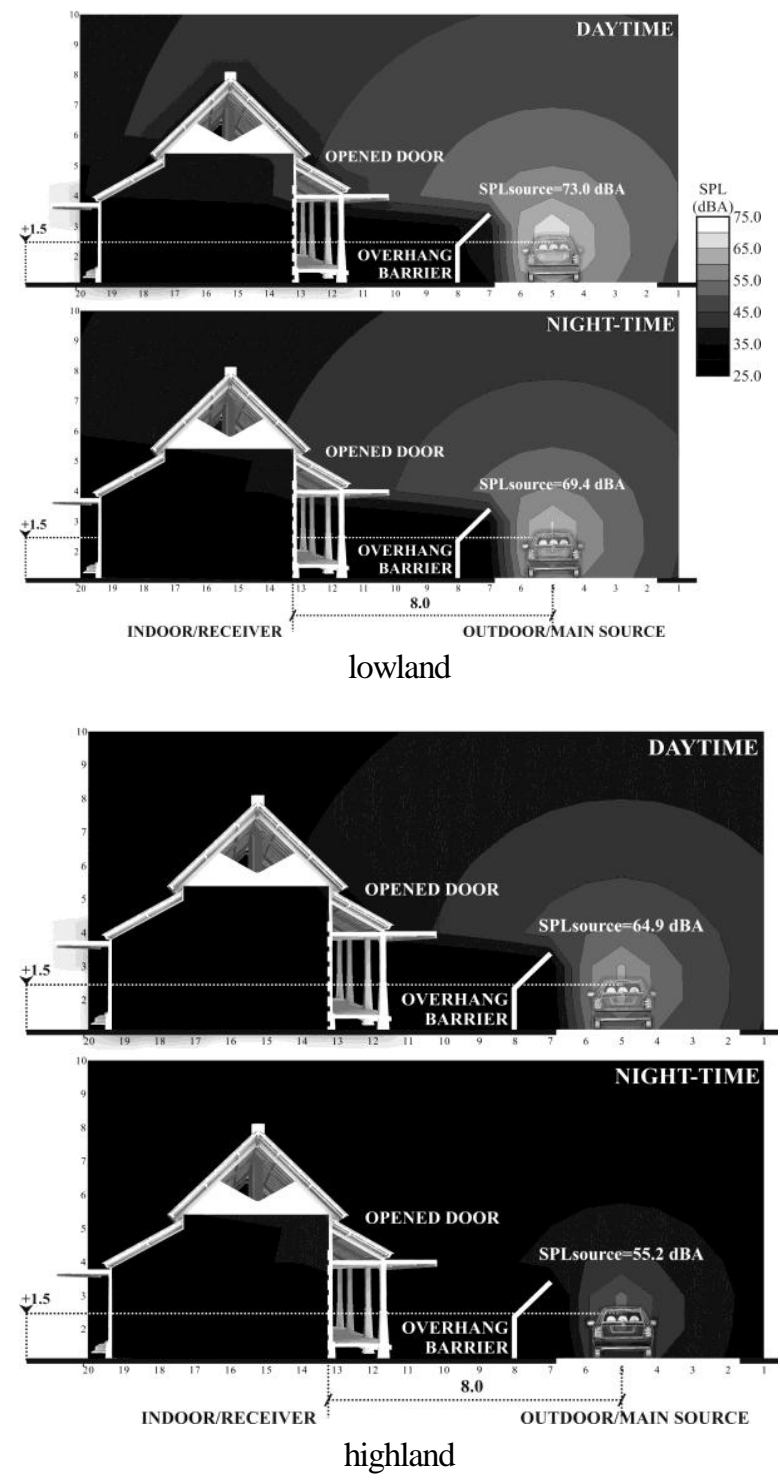

Fig. 8. Total noise propagation simulation with overhang barrier 


\section{Optimization on Thermal Comfort and Noise Control}

The optimization of height and position of site barrier for integrating thermal comfort with noise propagation control is designed based on considerations as follows: (1). Reaching the standard (requirement) for both thermal and noise control, for both WHO standard and Field Study requirement; (2). Accelerating wind and reducing traffic noise from the same direction; (3). Architectural Reason: View (from and to building) and Space (enough for road and site circulation).

As shown in Figure 9, the minimum distance of barrier to receiver is very closed for field study noise limit and it is used for lowland building only. However, for WHO noise limit, the requirement is for all areas and time and it requires longer distance (Figure 10). The lowest distance for noise control is $1.8 \mathrm{~m}$ as indicated by lowland night-time condition. In addition, minimum distance for airflow (thermal improvement) is higher than for noise control. It means that ventilation for both air quality requirement (airflow and air change) and physiological cooling is more important. To meet all considerations above, the minimum distance of barrier to receiver in case of the lowest barrier height $(1.5 \mathrm{~m})$ should be $5.63 \mathrm{~m}$. For closer distance in high density of settlement, it will be problem. Therefore, in Figure 11, it is offered for closer distance with consequence on aperture reference height (the bottom height of aperture/ building opening from ground surface) to catch air movement.

Requirement of aperture reference height for reducing barrier distance to receiver shows that at minimum distance for noise control $(1.8 \mathrm{~m})$, the minimum reference height is $1.02 \mathrm{~m}$ when it uses 1.5 $\mathrm{m}$ of barrier height.

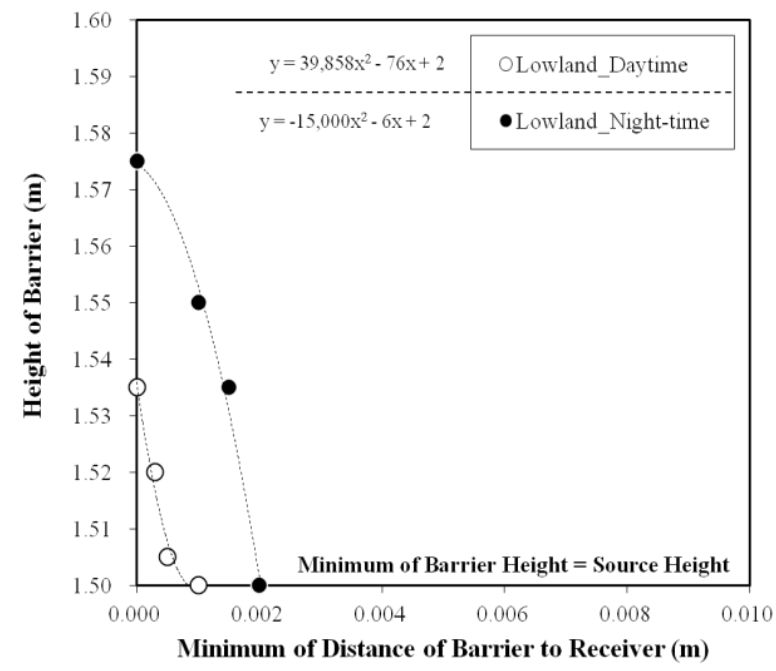

Fig. 9. Noise control requirement based on field study noise limits.
At average distance of barrier to receiver on existing buildings, $5 \mathrm{~m}$, the $1.5 \mathrm{~m}$ barrier height results $0.167 \mathrm{~m}$ of reference height, it is very accepted for building design where it needs to arrange of building aperture size and position. In detail, it can be summarized in Table 1. Actually, in case of tropical building in urban environment, the condition that minimum of openings affecting low wind speed and less distribution of existing is improved by raised floor and roof for providing better wind acceleration. Furthermore, the overhang barrier supports through deflecting the wind into building, something is rarely occurred using simple barrier only. By overhang barrier, noise control is also reached for all standards and conditions even though there is diffraction effect resulted by this barrier.

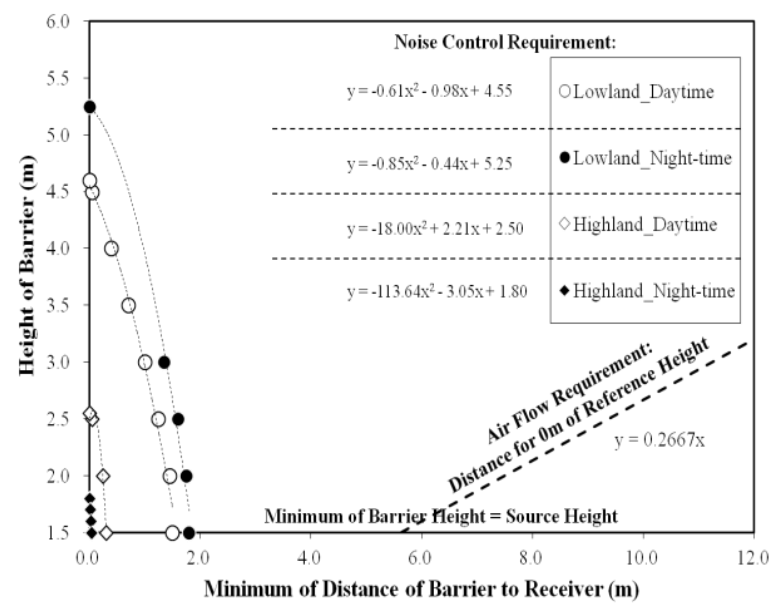

Fig. 10. Noise control and airflow requirement based on WHO noise limits.

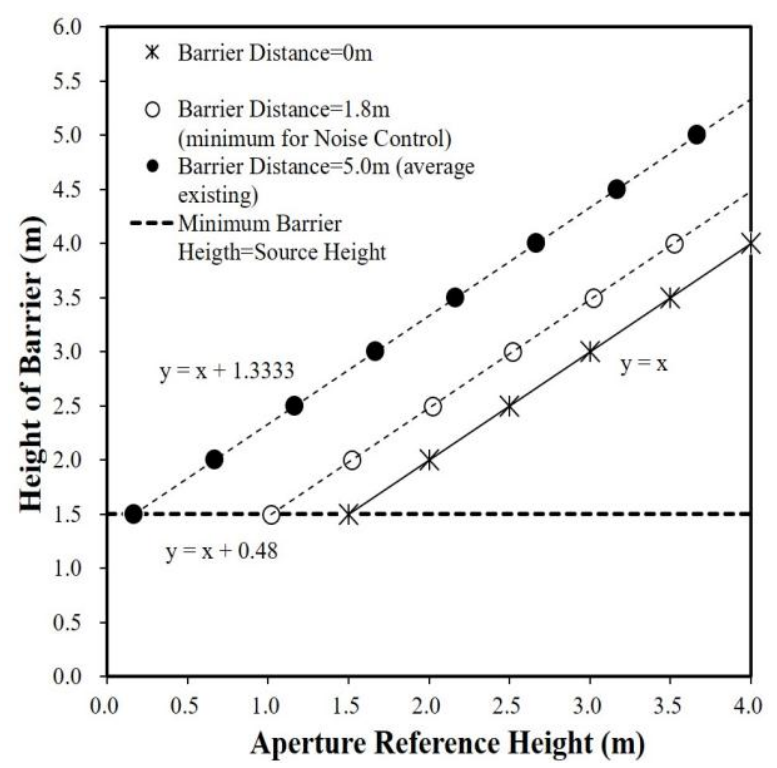

Fig. 11. Requirement aperture reference height for reducing barrier distance to receiver. 
Table 1. Summary for barrier for ventilation and controlling noise for various distance samples.

\begin{tabular}{|c|c|c|c|c|c|}
\hline \multirow{4}{*}{ Location/Time } & \multirow{4}{*}{$\begin{array}{l}\text { Height of } \\
\text { Barrier (m) }\end{array}$} & \multicolumn{4}{|c|}{ Requirement for Distance of Barrier to Receiver (m) } \\
\hline & & \multicolumn{2}{|c|}{ Field Study Limits } & \multicolumn{2}{|c|}{ WHO Standard } \\
\hline & & Minimum for Thermal & Minimum for Noise & Minimum for Thermal & Minimum for Noise \\
\hline & & Improvement & Improvement & Improvement & Improvement \\
\hline \multirow[t]{3}{*}{ Lowland/Daytime } & $1.5^{*}$ & 5.63 & 0.001 & 5.63 & 1.5 \\
\hline & $1.535 * *$ & 5.76 & 0 & - & - \\
\hline & $4.6^{* *}$ & - & - & 17.25 & 0 \\
\hline \multirow[t]{3}{*}{ Lowland/Night-time } & $1.5^{*}$ & 5.63 & 0.002 & 5.63 & 1.8 \\
\hline & $1.575^{* *}$ & 5.91 & 0 & - & - \\
\hline & $5.25 * *$ & - & - & 19.69 & 0 \\
\hline \multirow[t]{2}{*}{ Highland/Daytime } & $1.5^{*}$ & 5.63 & 0 & 5.63 & 0.3 \\
\hline & $2.55 * *$ & - & - & 9.56 & 0 \\
\hline \multirow[t]{2}{*}{ Highland/Night-time } & $1.5^{*}$ & 5.63 & 0 & 5.63 & 0.04 \\
\hline & $1.8 * *$ & - & - & 6.75 & 0 \\
\hline
\end{tabular}

*) minimum height of barrier = height of noise source

**) height of barrier for $0 \mathrm{~m}$ of barrier distance to receiver for noise control

\section{CONCLUSION}

In line with Samodra et al (2014), the aperture area included porous walls of tropical buildings can provide a thermal improvement, but allow noise problem from outdoors to indoors when the wind is in the same direction as the noise source. However, in this study, despite the different geographical locations, compromise between the barrier design and preserving the original tropical material can help to solve the environmental heat and noise simultaneously. Meanwhile, as recommended by Indonesian guidelines of Construction and Building, Department of Settlement and Infrastructure (Pd T-16-2005-B), about Prediction of Noise Due to Traffic and Mitigation of Impacts Due to Road Traffic Noise, by complying all requirements above, the overhang barrier has capability in reducing about $25 \mathrm{dBA}$. It meets with $10-15$ of guideline even though the distance is very closed in the Noise Risk Areas ( $8 \mathrm{~m}$ from noise source). In general, by site barrier improvement, the opened door has possibility to be freely scheduled and located, as well as accelerating the air movement through creating overhang. Overhang for barrier is useful not only for deflecting the air, but also to enclosing the road noise.

\section{REFERENCES}

Aynsley, R.M., Melbourne, W. \& Vickery, B.J. (1977). Architectural Aerodynamics. Applied Science, London.

Aynsley, R.M. \& Spruill, M. (1990). Thermal comfort models for outdoor thermal comfort in warm humid climates and probabilities of low wind speeds. Journal of Wind Engineering and Industrial Aerodynamics, 36, pp. 481-488.
Berglund, B., Lindvall T., Schwela D. \& Goh, K.T. (2000). Guidelines for Community Noise. Geneva: World Health Organization (WHO).

Boutet, T.S. (1987). Controlling air movement: A manual for architects and builders. McGraw Hill, USA.

Construction and Building, Department of Public Work (Pd T-16-2005-B). Mitigation of Impacts Due to Road Traffic Noise.

Ghiaus, C., Allard, F., Santamouris, M., Georgakis, C. \& Nicol, F. (2006). Urban environment influence on natural ventilation potential. Building and Environment, 41, pp. 395-406.

Huang, L., Zhu Y., Ouyang, Q. \& Cao, B. (2012). A study on the effects of thermal, luminous, and acoustic environments on indoor environmental comfort in offices. Building and Environment, 49, pp. 304-309.

Lai, A.C.K., Mui, K.W., Wong, L.T. \& Law, L.Y. (2009). An evaluation model for indoor environmental quality (IEQ) acceptance in residential buildings. Energy and Buildings, 41, pp. 930-936.

Sakamoto, S. (2015). Road traffic noise prediction model "ASJ RTN-Model 2013": Report of the research committee on road traffic noise. Acoust. Sci. \& Tech, 36(2), pp. 49-108.

Samodra, F.X.T.B.S., Yum, S.K. \& Yoon, S.H. (2014). Experimental study on thermal and noise environment in Indonesian Javanese houses. International Conference on The Yellow Sea Rim International Exchange Meeting on Building Environment and Energy (YSRIM 2014), Busan, Korea, February 16-18, pp. 60-67.

Samodra, F.X.T.B.S. (2015). Environmental Psychology Survey on Traditional Building Occupant 
FX Teddy, B. S.

in Tropical Environment. International Seminar of Indonesian Students Association in Korea, Daejeon, Korea, September 5-6.
Yamamoto, K. (2010). Road traffic noise prediction model "ASJ RTN-Model 2008": Report of the research committee on road traffic noise. Acoust. Sci. \& Tech, 31(1), pp. 2-55. 